\title{
DIGITALCOMMONS
}

@WAYNESTATE-

Wayne State University

Biochemistry and Molecular Biology Faculty

Publications

Department of Biochemistry and Molecular

Biology

$1-5-1992$

\section{Structural changes that accompany the reduced catalytic efficiency of two semisynthetic ribonuclease analogs}

\author{
V. Srini J. de Mel \\ Department of Biochemistry, Wayne State University School of Medicine \\ Philip D. Martin \\ Department of Biochemistry, Wayne State University School of Medicine \\ Marilynn S. Doscher \\ Department of Biochemistry, Wayne State University School of Medicine \\ Brian FP Edwards \\ Department of Biochemistry, Wayne State University School of Medicine, bedwards@med.wayne.edu
}

Follow this and additional works at: https://digitalcommons.wayne.edu/med_biochem

Part of the Biochemistry Commons, and the Molecular Biology Commons

\section{Recommended Citation \\ de Mel, V. S., Martin, P. D., Doscher, M. S., and Edwards, B. F. P. Structural changes that accompany the reduced catalytic efficiency of two semisynthetic ribonuclease analogs, J. Biol. Chemistry 267: 247-256, 1992. https://doi.org/10.1016/s0021-9258(18)48486-4}

This Article is brought to you for free and open access by the Department of Biochemistry and Molecular Biology at DigitalCommons@WayneState. It has been accepted for inclusion in Biochemistry and Molecular Biology Faculty Publications by an authorized administrator of DigitalCommons@WayneState. 


\title{
Structural Changes That Accompany the Reduced Catalytic Efficiency of Two Semisynthetic Ribonuclease Analogs*
}

(Received for publication, April 30, 1991)

\author{
V. Srini J. deMel, Philip D. Martin, Marilynn S. Doscher, and Brian F. P. Edwards $\$$ \\ From the Department of Biochemistry, Wayne State University School of Medicine, Detroit, Michigan 48201
}

\begin{abstract}
The structures of two catalytically defective semisynthetic RNases obtained by replacing aspartic acid 121 with asparagine or alanine have been determined and refined at a resolution of $2.0 \AA(R=0.186$ and 0.172 , respectively). When these structures are compared with the refined $1.8-\AA$ structure $(R=0.204)$ of the fully active aspartic acid-containing enzyme (Martin, P. D., Doscher, M. S., and Edwards, B. F. P. (1987) J. Biol. Chem. 262, 15930-15938), numerous and widespread changes, much greater in number and magnitude than the small structural variations noted previously between the semisynthetic complex and RNase $A$, are found to have occurred. These changes include the movement of the loop containing residues 65-72 away from the active site, a more or less generalized relocation of crystallographically bound water molecules, and a number of rearrangements in the hydrogen bonding network at the active site. Most changes are far removed from the immediate site of the modifications and are distributed essentially throughout the molecule. The details of many of these changes are unique to each analog. In the asparagine analog, a destabilization in the positioning of active site residue His-119 also appears to have occurred.
\end{abstract}

The possible involvement of aspartic acid 121 in the mechanism of action of bovine pancreatic RNase $\mathrm{A}^{1}$ (EC 3.1.27.5)

* This work was supported in part by National Institutes of Health Grant GM 40630 and the Center for Molecular Biology at Wayne State University. The costs of publication of this article were defrayed in part by the payment of page charges. This article must therefore be hereby marked "advertisement" in accordance with 18 U.S.C. Section 1734 solely to indicate this fact.

$\ddagger$ To whom correspondence should be sent: Department of Biochemistry, Wayne State University, 540 E. Canfield Ave., Detroit, MI, 48201. Tel.: 313-577-1506; Fax: 313-577-2765.

1 The abbreviations used are: RNase A, bovine pancreatic ribonuclease A; RNase S, noncovalent complex of residues 1-20 and 21-124 formed by limited subtilisin digestion of RNase A; RNase 1-118, polypeptide consisting of residues 1-118 of RNase A; RNase 111-124, tetradecapeptide consisting of residues $111-124$ of RNase A; RNase 111-124(D121N), tetradecapeptide consisting of residues 111-124 of RNase in which Asp-121 has been substituted by asparagine; RNase 111-124(D121A), tetradecapeptide consisting of residues 111-124 of RNase in which Asp-121 has been substituted by alanine; RNase 111-124(F120Y), tetradecapeptide consisting of residues 111-124 of RNase in which Phe-120 has been substituted by tyrosine; RNase 1118:111-124, noncovalent complex of RNase 1-118 and RNase 111124 , also referred to as the "parent complex"; D121N, noncovalent complex of RNase 1-118 and RNase 111-124(D121N), also referred to as the "asparagine analog"; D121A, noncovalent complex of RNase 1-118 and RNase 111-124(D121A), also referred to as the "alanine analog"; F120Y, noncovalent complex of RNase 1-118 and RNase 111-124(F120Y); $\quad \mathrm{O}^{3} 2^{\prime}$-CMP, cytidine- $N$-(3)-oxide-2'-phosphate; T-H12-RNase, [ $N^{\prime 2}$ - $\left[\left[\left[\left(3^{\prime}\right.\right.\right.\right.$ - deoxy - $3^{\prime}$ - thymidinyl $)$-amino $\}$ carbonyl $]$ methyl]histidine-12] ribonuclease A; U-H119-RNase, [ $N^{s t}$-[[[ $\left(3^{\prime}\right.$ - was first postulated by Anfinsen (1956) who observed that the rate of inactivation of the enzyme paralleled the rate of removal of its C-terminal tetrapeptide by peptic proteolysis. Subsequently, in crystals grown from aqueous alcohol at $\mathrm{pH}$ 5.2 , this residue was seen to be within hydrogen bonding distance of His-119, a confirmed component of the active site (Wlodawer and Sjölin, 1981; Wlodawer et al., 1982). Aspartic acid 121 is also an invariant residue across 40 species of mammalian pancreatic RNases (Beintema et al., 1988).

The hypothesis that Asp-121 is important for enzymatic activity has been tested by the preparation and kinetic analysis of two semisynthetic analogs of the enzyme in which this residue is replaced by asparagine or alanine. The semisynthetic enzyme consists of a noncovalent complex of residues 1-118 of RNase A, obtained by partial enzymatic digestion of the protein with pepsin and carboxypeptidase A, and a synthetic tetradecapeptide peptide containing the $14 \mathrm{C}$-terminal residues of RNase A (Lin et al., 1970) (Fig. 1). This noncovalent complex, denoted RNase 1-118:111-124, exhibits in full the transphosphorylytic and hydrolytic activities seen with RNase A (Lin et al., 1970; Gutte et al., 1972). Also, the titration behavior of its 4 histidine residues (including active site histidines 12 and 119) as revealed by proton NMR measurements is indistinguishable from that observed for these same residues in RNase A (Doscher et al., 1983a; Cederholm et al., 1991). A refined 1.8-A structure of crystals of RNase 1118:111-124 grown from concentrated salt solution at $\mathrm{pH} 5.2$ has been obtained (Martin et al., 1987). When asparagine replaced Asp-121 in this complex, the activity against cytidine cyclic $2^{\prime}, 3^{\prime}$-phosphate was first reported to be $4 \%$ of that exhibited by the aspartic acid-containing structure (Merrifield and Hodges, 1975). Subsequently, a $k_{\text {cat }}$ value against the same substrate of $2 \%$ was found (Stern and Doscher, 1984). Measurements with the same substrate at $\mathrm{pH} 6.0$ have now provided the kinetic parameters shown in Table $\mathrm{I}$. The alanine analog has a somewhat greater, but still significantly reduced, $k_{\text {cat }}$ value against this same substrate (Table I). Activity toward yeast RNA is also reduced to a value of $5 \%$ for the asparagine analog and to $48 \%$ for the alanine analog (Stern, 1988). Using a somewhat different semisynthetic RNase system, Irie and co-workers have also found significant reductions in both transphosphorylytic and hydrolytic activities upon replacement of Asp-121 with either asparagine or alanine (Okada et al., 1984; Irie et al., 1988).

We report here the 2.0 - $\AA$ refined structures of the Asn-121 and Ala-121 analogs, obtained from crystals grown under conditions identical to those used to crystallize RNase 1118:111-124 (Doscher et al., 1983b). Crystals of both analogs proved to be in the same space group and to have very nearly

deoxy-3'-uridinyl)amino]carbonyl]methyl]histidine-119] ribonuclease A; UpA, uridylyl-3',5'-adenosine; UpcA, UpA in which the $5^{\prime}$ oxygen of the ribose moiety of the adenosine is replaced by a methylene group. RMS, root mean square. 


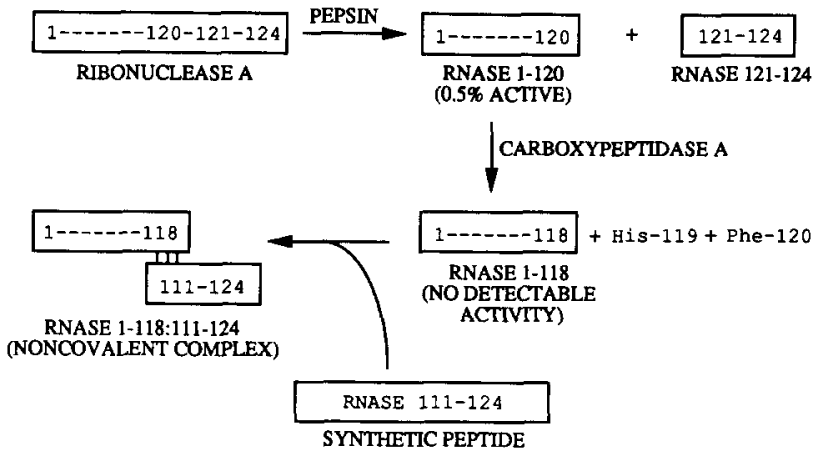

FIG. 1. Preparation and assembly of RNase 1-118:111124. The schematic diagram shows the synthesis of RNase 1-118 by proteolytic digestion and its assembly with a chemically synthesized 111-124 peptide into a noncovalent complex (which is fully active when no amino acid replacements have been made).

TABLE I

Kinetic parameters for cytidine cyclic $2^{\prime}, 3^{\prime}$-phosphate

\begin{tabular}{lccc}
\hline \multicolumn{1}{c}{ Species } & $K_{M}$ & $k_{\text {cat }}$ & Ref. \\
\hline & $m M$ & $s^{-1}$ & \\
RNase A $^{a}$ & $1.66 \pm 0.09$ & $7.6 \pm 0.4$ & $b$ \\
RNase A $^{c}$ & $2.6 \pm 0.3$ & $2.1 \pm 0.2$ & \\
RNase 1-118:111-124 $^{d}$ & 0.7 & $-^{e}$ & $f$ \\
RNase 1-118:111-124 & $1.1 \pm 1.0$ & $2.1 \pm 0.8$ & \\
(D121N) $^{g}$ & $4.3 \pm 0.6$ & $0.22 \pm 0.02$ & \\
(D121A) $^{i}$ & $1.9 \pm 0.8$ & $0.47 \pm 0.09$ & \\
\hline
\end{tabular}

${ }^{a}$ Assay conditions: $0.20 \mathrm{M} \mathrm{KCl}, \mathrm{pH}$ maintained at 6.00 with a pHstat, $25^{\circ} \mathrm{C}, 0.92-8.8 \mathrm{mM}$ substrate, RNase concentration not given. Standard deviations are given.

${ }^{b}$ Herries et al. (1962).

'Assay conditions: $0.20 \mathrm{M} \mathrm{NaCl}, 0.10 \mathrm{M}$ sodium malonate, $\mathrm{pH} 6.00$, $25^{\circ} \mathrm{C}, 0.58-6.0 \mathrm{mM}$ substrate, $0.19 \mu \mathrm{M}$ RNase. Velocity determinations were made in quadruplicate, and standard error values are given.

${ }^{d}$ Assay conditions: $0.10 \mathrm{M} \mathrm{NaCl}, 0.10 \mathrm{M}$ Tris acetate, $\mathrm{pH} 6.0,25^{\circ} \mathrm{C}$, 0.1-0.9 mM substrate, RNase 1-118 concentration not given.

${ }^{e}$ No $k_{\text {cat }}$ value was given, but activity at saturating ratios of RNase 111-124 to RNase 1-118 was stated to be $98 \%$ of that for an equimolar amount of RNase A.

' Lin et al. (1972).

${ }^{g}$ Buffer, temperature, and concentration range of substrate were the same as in Footnote $c$; RNase $1-118$ was $0.28 \mu \mathrm{M}$. The velocity determinations were made in quadruplicate at four progressively higher mol ratios of RNase 111-124 to RNase 1-118, and the maxima velocity at saturating levels of peptide was determined by extrapolation of a double-reciprocal plot of velocity versus molar ratio.

${ }^{n} \mathrm{As}$ in Footnote g, except that RNase $1-118$ was $3.36 \mu \mathrm{M}$.

is in Footnote $g$, except that RNase $1-118$ was $1.68 \mu \mathrm{M}$.

the same unit cell dimensions as the fully active parent complex (Martin et al., 1987; see Table II). The details of the structural differences between the two analogs and the parent complex, as well as those between the two analogs, are described, and possible structural bases for the loss of catalytic efficiency in these analogs are discussed.

\section{EXPERIMENTAL PROCEDURES}

Materials-RNase A (type XII-A) used in the preparation of RNase 1-118 was purchased from Sigma as were carboxypeptidase A (type I-DFP), its substrate, hiippuryl-L-phenylalanine, pepsin (P-6887) and cytidine cyclic $2^{\prime}, 3^{\prime}$-phosphate, sodium salt (C9630).

Preparation of RNase 1-118-RNase 1-118 was prepared according to procedures published previously (Doscher et al., 1983a), except that the gel-filtered product was further purified by isocratic ionexchange chromatography at $5^{\circ} \mathrm{C}$ on SP-Sephadex G-25, 40-120 $\mu \mathrm{m}$ (0.13 M sodium phosphate, $\mathrm{pH}$ 6.65). Stock solutions of RNase 1-118 were characterized by amino acid analysis of acid hydrolysates of aliquot samples and by the determination of specific activity against cytidine cyclic $2^{\prime}, 3^{\prime}$-phosphate, both in the absence and in the pres- ence of a saturating level of RNase 111-124. Activity against this substrate was determined as described previously (Sasaki et al., 1985).

Synthesis of RNase 111-124(D121N) and RNase 111-124(D121A)The tetradecapeptide analogs were synthesized by the Wayne State University Macromolecular Core Facility and purified by methods described previously (Doscher et al., 1983a). Stock solutions of the peptides were characterized and standardized by amino acid analysis of acid hydrolysates of aliquot samples.

Crystallization-Crystals of RNase 1-118:111-124 and the two analogs were all grown from ammonium sulfate/cesium chloride salt solutions buffered at pH 5.2 as described earlier (Sasaki et al., 1979; Doscher et al., 1983b). CsCl was removed by transferring the crystals into a stabilizing buffer of $80 \%$ saturated ammonium sulfate, $0.1 \mathrm{M}$ ammonium acetate, $\mathrm{pH}$ 5.2. Individual crystals were soaked between 2 and $4 \mathrm{~h}$, with several changes of solution, before being mounted in a glass capillary in the usual way. The crystals deteriorated noticeably if stored in the absence of $\mathrm{CsCl}$ longer than a week.

Data Collection-Area detector data were collected for the asparagine and alanine analogs on a Siemens system employing a threeaxis camera, a PCS driven controller, and the XENGEN software package (Howard et al., 1987) supported on a VAX 3600 minicomputer. The crystals were mounted in a random orientation, the detector was moved $8.0 \mathrm{~cm}$ away from the crystal, and $2 \theta$ was set to $26^{\circ}$. Frames of data were collected so that a $0.25^{\circ}$ oscillation in $\omega$ accumulated between two and three million counts in a time period determined for each crystal. This period was usually $3-5 \mathrm{~min}$ using the Rigaku RU200H rotating anode generator at $40 \mathrm{kV}$ and $70 \mathrm{~mA}$, a Supper graphite monochromator, and a $0.3-\mathrm{mm}$ collimator. After the first "sweep" of 440 frames $\left(110^{\circ}\right), \phi$ was rotated $70^{\circ}$ away from its previous setting and the process was repeated for another 440 frames. These data were indexed, merged, and scaled, using only data for which $\mathrm{I}>2 \sigma(\mathrm{I})$. The intensities were reduced to structure amplitudes with the XENGEN program using three alternating runs of $P 1$ scaling (15-20 cycles) and batch deletions with $Q$ values of 9,6 , and a final $Q$ determined by the software, followed by one last scaling run. This procedure permitted the collection of approximately $80 \%$ of the available $2 \sigma$ data before the crystals decayed. As there was no internal measure of decay, alignment statistics with 50 frames of data were used as a rough measure of the quality of the crystal. Attempting to get missing reflections by making a third sweep significantly harmed the $R_{\text {aym }}$ values while adding very little to the data.

Refinement-Refinement by simulated annealing was performed with the XPLOR program (Brünger, 1988) on an IRIS4D/85GT computer using standard generate, checkstage, prepstage, coolstage, finalstage and refinement inputs, except that the "pele" and "pvdw" parameters were not invoked. All simulated annealing refinements used the slow cool annealing protocol with the dynamics temperature starting out at $4,000 \mathrm{~K}$ and decreasing in intervals of $25 \mathrm{~K}$ to a final temperature of $0 \mathrm{~K}$ with 25 steps $(0.5 \mathrm{fs} / \mathrm{step})$ of Verlet dynamics at each temperature.

Refinement with ROTLSQ and PROLSQ was handled almost identically as with the parent enzyme (Martin et al., 1987), except that a version of the program which restrains symmetry-related intermolecular contacts (PROFFT) as well as the B-refinement in XPLOR was used in the final stages of each refinement. A solvent molecule was added and retained if the electron density peak 1) appeared in $\mathrm{F}_{\mathrm{o}}-\mathrm{F}_{\mathrm{c}}$ maps at greater than $3.5 \sigma ; 2$ ) appeared in $2 \mathrm{~F}_{\mathrm{o}}-\mathrm{F}_{\mathrm{c}}$ maps at greater than $0.7 \sigma$; and 3 ) was within hydrogen bonding distance of an appropriate atom.

Modeling Studies - Coordinates for the RNase A-uridine vanadate complex (File 6RSA; Wlodawer et al., 1983) and RNase S (File 1RNS; Richards and Wyckoff, 1973) were obtained from the Protein Data Bank (Bernstein et al., 1977). Coordinates for UpcA were obtained from Richards and Wyckoff (1973). Both RNase A/uridine vanadate and $\mathrm{RNase} \mathrm{S} / \mathrm{UpcA}$ coordinate sets were rotated against the parent structure using the program OVRLAP (Rossman and Argos, 1975). With the RNase A/uridine vanadate set, the RMS value for the overlap of the $C_{\alpha}$ positions was $0.41 \AA$ and the corresponding value for the RNase $\mathrm{S} / \mathrm{UpcA}$ set was $0.51 \AA$.

Hydrogen Bonds-In evaluating hydrogen bonds, cutoff values of $3.5 \AA$ for the donor atom to acceptor atom distance and of $110^{\circ}$ for the donor atom-hydrogen atom-acceptor atom angle were used. When comparing two structures, a change in bond distance was considered significant if it was greater than $0.30 \AA$. This limit is more than twice the standard deviation of the differences between the main chain hydrogen bond distances of residues $2-110$ in the parent versus the D $121 \mathrm{~N}$ structure $(0.14 \AA)$ and in the parent versus the D121A structure $(0.12 \AA)$. 
TABLE II

Data collection and refinement

\begin{tabular}{lccc}
\hline \multicolumn{1}{c}{ Statistics } & $\begin{array}{c}\text { RNase } \\
1-118: 111-124^{a}\end{array}$ & D121N & D121A \\
\hline Unit cell $(\AA)^{b}$ & $a=67.68$ & $a=64.7$ & $a=64.73$ \\
& $c=65.03$ & $c=64.9$ & $c=64.92$ \\
Reflections used & 12,117 & 9,604 & 10,236 \\
Percent of total data & 89.5 & 84.8 & 90.7 \\
Resolution & $10-1.8$ & $5-2.0$ & $5-2.0$ \\
$R_{\text {sym }}(\mathrm{I})$ & 0.116 & 0.078 & 0.051 \\
$R$ after ROTLSQ & 0.360 & 0.280 & 0.294 \\
$R$ after X-PLOR cool- & & 0.251 & 0.246 \\
$\quad$ stage & & & \\
$R$ after PROLSQ & 0.204 & 0.193 & 0.183 \\
$R$ after X-PLOR B re- & & 0.186 & 0.172 \\
$\quad$ finement & & & \\
RMS bonds & 0.025 & 0.025 & 0.025 \\
RMS $\omega$ angle & 1.6 & 1.7 & 1.8 \\
\hline
\end{tabular}

${ }^{a}$ From Martin et al. (1987). Also, Protein Data Bank File 1SRN (Bernstein et al., 1977).

${ }^{b}$ All structures belong to space group $\mathrm{P}_{2} 21$ and have one molecule/ asymmetric unit.

\section{RESULTS}

Data Collection, Structure Determination and RefinementThe diffraction data and final refinement statistics for the parent, D121N, and D121A semisynthetic ribonucleases are summarized in Table II.

Crystals of both the analogs belong to the same space group as the parent molecule, but the unit cells are not isomorphous. Consequently, several cycles of rigid body refinement (ROTLSQ) were run in each case to find the orientation and position of the molecule. Application of the X-PLOR package of programs then lowered the $R$ factors to 0.251 for D $121 \mathrm{~N}$ and 0.246 for D121A. The refinements were continued using PROLSQ and PROFFT and adding water molecules as well as a sulfate ion at the active site until convergence was reached. The final $R$ factors are 0.186 for $\mathrm{D} 121 \mathrm{~N}$ and 0.172 for D121A. ${ }^{2}$

The RMS differences for $\mathrm{C}_{\alpha}$ atoms between the parent structure and the asparagine and alanine analogs are $0.35 \AA$ and $0.38 \AA$, respectively, indicating that the overall structure of the molecule has been left virtually unchanged. The patterns of $\mathrm{C}_{\alpha}$ displacements (Fig. 2) are similar in both analogs with the most dramatic shifts being seen in the segments comprised of residues 31-42 and 86-94 and in the disulfidecontaining loop comprised of residues 65-72. Significant differences between the two analogs with respect to certain side chain displacements are evident, however (Fig. 3). The temperature factors for D121A (Fig. 4) did not, in general, differ greatly from those seen for the parent structure or for D121N.

Comparison of Main Chain Atoms-The replacement of Asp-121 by asparagine or alanine has resulted in numerous changes in structure throughout the molecule, but the major elements of secondary structure remain essentially unchanged. As was the case with the parent complex, residues 1-113 of RNase 1-118 and residues 114-124 of the peptides are seen, but there is no electron density for the redundant residues. The intramolecular main chain hydrogen bonding pattern in the analogs is in large part similar to that seen in RNase A (Wlodawer and Sjölin, 1983) and in RNase 1118:111-124 (Martin et al., 1987) (Fig. 5).

The Positioning of Loop 65-72-Upon the substitution of Asp-121 with either asparagine or alanine, the loop formed

${ }^{2}$ The coordinate sets for RNase 1-118:111-124 (File 1SRN), D121N (File 2SRN), and D121A (File 3SRN) are available from the Protein Data Bank (Bernstein et al., 1977). by the disulfide bond connecting half-cystine residues 65 and 72 moves away from the active site of the enzyme (Fig. 6). The value of the RMS difference for the positions of the $\mathrm{C}_{\alpha}$ atoms of residues $66-68$ is $0.84 \AA$ for D121N and $1.16 \AA$ for D121A. The most pertinent element of this change appears to be the movement of the side chain of Lys-66 and the consequences that follow this movement; the details of this repositioning are given under "Lysine 66."

General Features of the Water Structure-A total of 115 crystallographically bound water molecules now has been identified in RNase 1-118:111-124, using the criteria described under "Experimental Procedures." The number of waters remains nearly the same in the alanine analog, i.e. a total of 111, but increases to 132 in the asparagine analog. Of the water molecules within $3.5 \AA$ of a nitrogen or oxygen belonging to the protein, that is, those comprising the first shell of water, only 15 are common to RNase 1-118:111-124 and both analogs. This number equals a quarter of the firstshell water found in the parent structure. An additional 7 are common between the parent structure and D121N (for a total of 22), and an additional 11 are common between the parent structure and D121A (for a total of 26). The changes in water structure that these numbers imply are not strikingly localized but can be seen in a number of patches on the surface of the protein.

Active Site Histidine 12-The positioning of His-12 has not been disturbed significantly by the replacement of Asp-121 with either asparagine or alanine. As in the unmodified semisynthetic enzyme, the NE2 of this residue forms a short hydrogen bond to $\mathrm{O} 4$ of the sulfate at the active site in both analogs (Table III). The hydrogen bonds between ND1 of the ring and the carbonyl oxygen of Thr-45 and between ND1 of the ring and OD1 of Asn-44 are also unchanged in both cases (Table III).

Active Site Histidine 119-In RNase 1-118:111-124, the side chain of His-119 is found predominantly in a conformation first reported as a minor (20\%) occupancy in RNase A crystallized from aqueous ethanol at $\mathrm{pH} 5.2-5.7$ and denoted position B (Borkakoti et al., 1982, 1984; also our Fig. 7). The $\chi 1$ value for position $B$ is $-60^{\circ}$ whereas for the alternative conformation, known as position $A$, the value is $149^{\circ}$. Position $B$ is found to be the predominant conformation for His-119 in both the asparagine and alanine analogs as well (Fig. 7). The positioning of the imidazole ring in the analogs is not exactly coincident with that found in the parent complex, however, as the ring has shifted approximately $0.5 \AA$ toward the sulfate in both cases (Fig. 8 and Table III). In neither case has the plane of the ring changed significantly.

The conformation of His-119 in the asparagine analog appears to have an additional complexity as revealed by the hydrogen bonding pattern of the imidazole ring of this residue. In this analog, a water molecule (WAT 126) is positioned to make a hydrogen bond ( $3.13 \AA$ ) with what would be the CD2 of the imidazole ring if the orientation based on mechanistic considerations (e.g. Findlay et al., 1962) and neutron diffraction experiments (Wlodawer and Sjölin, 1981) is assumed; that is, with ND1 facing toward the sulfate anion and hydrogen bonding to the $\mathrm{O} 2$ atom of the anion. WAT 126 is seen in neither the parent structure nor the alanine analog. The distance between WAT 126 and NE2 of the imidazole ring when conventionally oriented is $5.3 \AA$ and so is not compatible with the formation of a hydrogen bond. This anomaly could be reconciled, however, if the imidazole ring were flipped $180^{\circ}$ so that ND1 now occupied the CD2 position. Of course, such a flip would then place $\mathrm{CD} 2$ adjacent to the $\mathrm{O} 2$ of the sulfate. Active Site Lysine 41-As was the case for RNase 1- 
Fig. 2. Comparison of the $\mathrm{C}_{\alpha}$ structures. The structures of RNase 1118:111-124 (solid line), D121N (dotted line), and D121A (dashed line) were overlapped using residues $2-110$ and the program OVRLAP (Rossman and Argos, 1975).

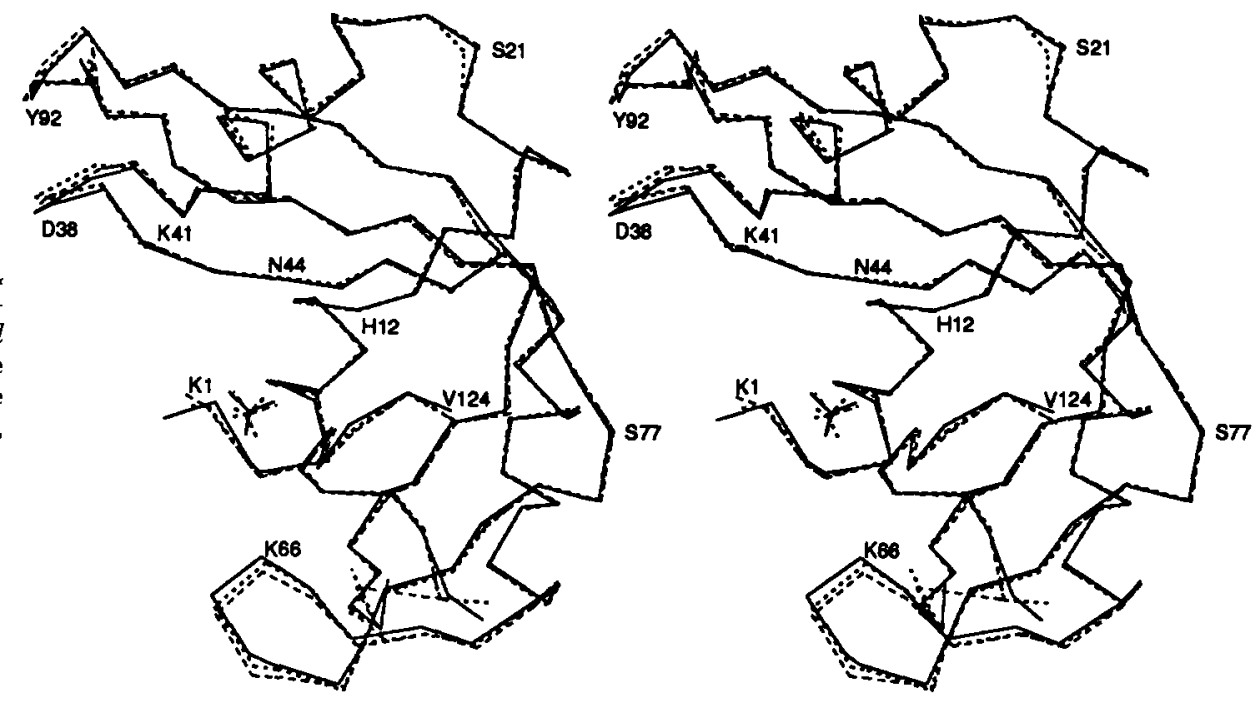

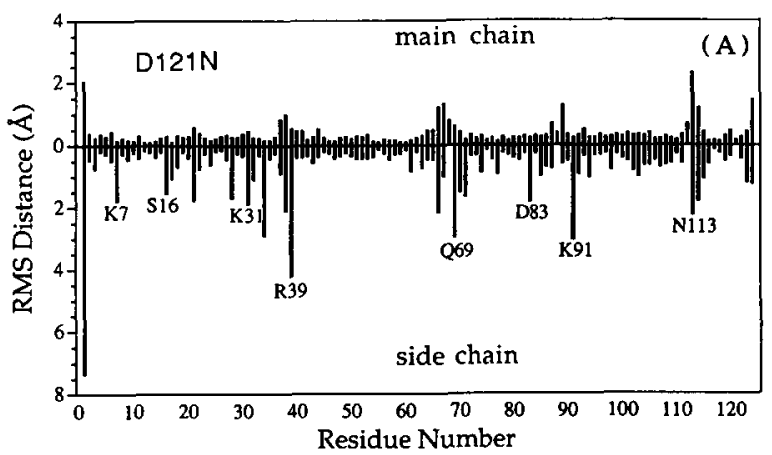

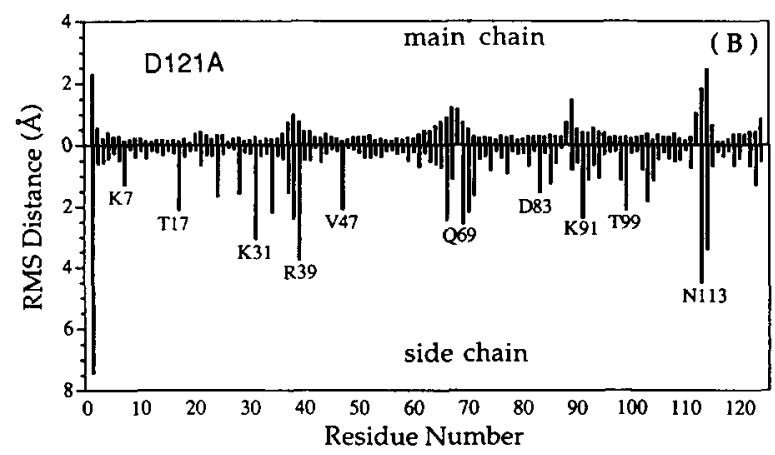

FIG. 3. RMS displacements compared with the parent structure. RMS displacements of main chain and side chain atoms. $A$, D121N relative to those of RNase 1-118:111-124; $B$, D121A relative to those of RNase 1-118:111-124, plotted as a function of residue number. The structures were overlapped as in Fig. 2.

118:111-124, all the side chain atoms of Lys-41 were found to be in good density in both analogs. The hydrogen bonding pattern of this residue remains qualitatively unchanged in both analogs, but significant changes in bond lengths have occurred in both structures. Again, these changes are unique to each analog (Table III).

Active Site Glutamine 11-The hydrogen bond between NE2 of Gln-11 and the water molecule bridging this side chain to the $\mathrm{O} 4$ of the sulfate is not perceptibly affected by the replacement of Asp-121 with asparagine or alanine. Other interactions have been disturbed, however. The hydrogen bond between NE2 and a water (WAT 228) that was also hydrogen bonded to $\mathrm{O} 3$ of the sulfate is gone in both analogs, as is the water itself. The third hydrogen bond formed by

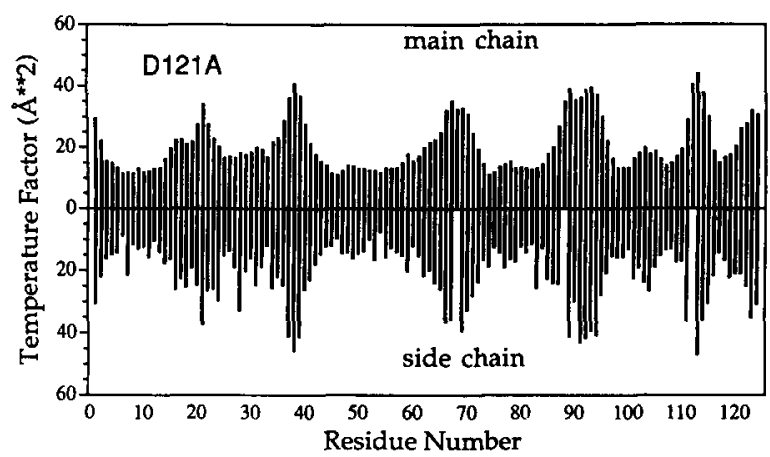

Fig. 4. Temperature factors. The average temperature factors for the four main chain as well as the side chain atoms of each residue are plotted as a function of residue number for D121A. With a few exceptions, similar values were found for D121N and for RNase 1118:111-124.

NE2 in the parent structure, namely, that directly with the sulfate 03 , is gone in the asparagine analog and significantly lengthened in the alanine analog (Table III).

Active Site Asparagine 121/Alanine 121-The main chain atoms of Asn-121 in D121N are coincident with the corresponding atoms of Asp-121 in RNase 1-118:111-124, but the relative positioning begins to diverge with $\mathrm{CB}(\delta, 0.31 \AA)$ and progressively increases: CG $(\delta, 0.64 \AA), \operatorname{OD} 1(\delta, 0.81 \AA)$, and ND2 $(\delta, 0.88 \AA)$. Of the three hydrogen bonding interactions made by Asp-121 with Lys-66 in RNase 1-118:111-124 (see "Lysine 66"), only that between the backbone nitrogen of Lys-66 and what is now a carboxamide oxygen of the 121 side chain remains. The positioning of even that bond has shifted significantly. A new, long hydrogen bond $(3.48 \AA)$ has formed between the NZ of Lys- 66 and the carboxamide oxygen. The electrostatic interaction between the carboxylate of Asp-121 and the positively charged $\epsilon$ amino group of Lys-66 is, of course, also absent.

The main chain atoms and CB of Ala- 121 in D121A also are all coincident with the corresponding atoms of Asp-121 in RNase 1-118:111-124. The volume occupied by the carboxylate group in the parent complex and by the carboxamide group in D121N is partially filled with a water molecule (WAT 400).

Active Site Solvent Molecules-Two water molecules found at the active site in RNase 1-118:111-124 are retained in both 
the analogs, but the nature and strength of the hydrogen bonds made by these waters are changed, generally in a way that is unique to each analog (Table III). The $B$ value for one of these water molecules (WAT 153) has almost exactly doubled in both analogs (46 $\AA^{2}$ for D121N and $58 \AA^{2}$ for D121A versus $24 \AA^{2}$ for RNase 1-118:111-124) whereas the B value for the second water molecule (WAT 138) is virtually unchanged (18 $\AA^{2}$ for D121N and $17 \AA^{2}$ for D121A versus 18 $\AA^{2}$ for RNase 1-118:111-124). A water molecule coincident with WAT 138 is also found in both refined structures of RNase A (Wlodawer and Sjölin, 1983; Borkakoti et al., 1984).

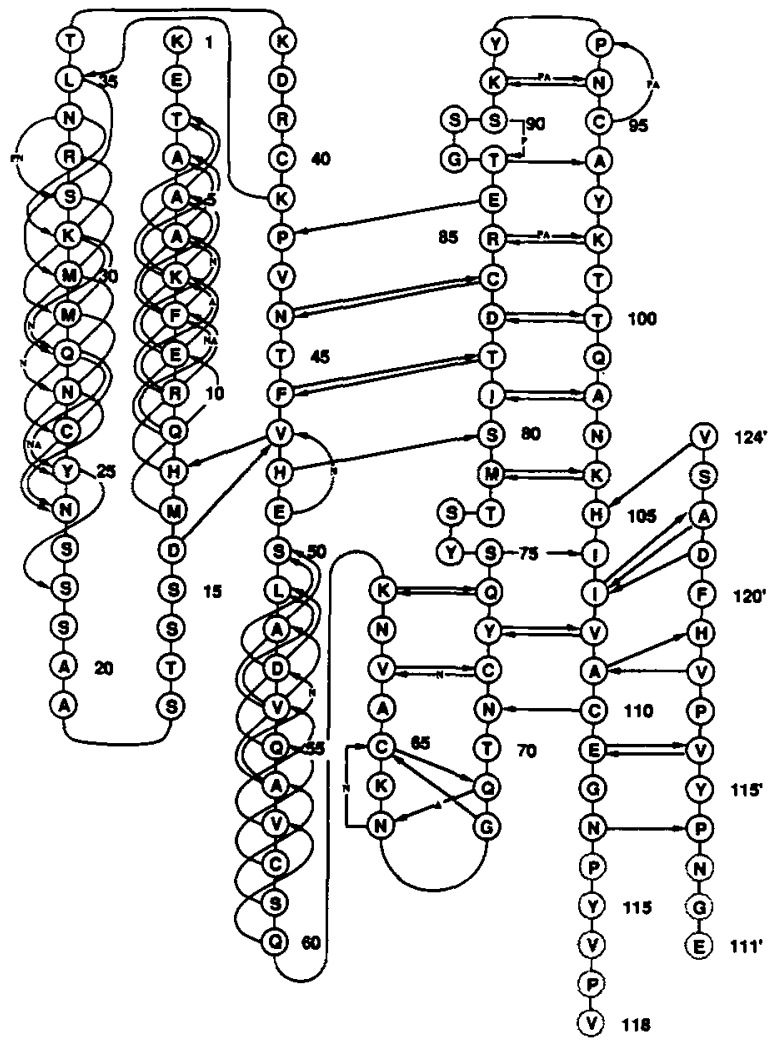

FIG. 5. Backbone hydrogen bonding scheme. Backbone hydrogen bonds with a donor-acceptor distance less than $3.5 \AA$ and an angle greater than $110^{\circ}$ are shown for RNase 1-118:111-124 (label = $P$ ), D121N (label $=N$ ), and D121A (label $=A$ ). Hydrogen bonds without any label are present in all three structures. The arrows go from donor to acceptor.
A third water (WAT 228) at the active site of RNase 1118:111-124, seen hydrogen bonding to NE2 of Gln-11 and $\mathrm{O} 3$ of the sulfate, is missing in both analogs. A new water (WAT 126) is seen at the active site of D121N, however, and it appears to be hydrogen bonded to the ND1 of an alternative conformation of His-119 (see above).

Active Site Sulfate Anion-As indicated, the sulfate anion found at the active site of RNase 1-118:111-124 is retained in both analogs. The coordinates of the sulfur atom itself are not perceptibly changed in either analog, but there is a significant reduction in the net number of hydrogen bonding interactions in both cases, with the loss being more severe in the case of the asparagine analog. The overall positioning of the sulfate oxygens is clearly different in $\mathrm{D} 121 \mathrm{~N}$, however, whereas this is not so for D121A. Of the 12 hydrogen bonds in RNase 1-118:111-124 that are formed by the four sulfate oxygens with water or with atoms of the protein, five are not seen in D121N, and one of the remaining bonds is significantly longer (Table III). Only 3 of the 12 hydrogen bonds are lost by the sulfate oxygens in the alanine analog, but an additional 3 hydrogen bonds are longer than in RNase 1-118:111-124. The net loss of bonds is only 2, however, as $\mathrm{O} 1$ now makes a hydrogen bond to WAT 197 (Table III). Two of the hydrogen bonds involving sulfate oxygens are significantly shortened in D121A, namely those between sulfate 125 O2 and H119 ND1 and between sulfate $125 \mathrm{O} 3$ and WAT 153 .

Lysine 66--In RNase A and RNase 1-118:111-124 three hydrogen bonds link Lys-66 and Asp-121. There is a strong hydrogen bond between the NZ of Lys-66 and the main chain carbonyl of Asp-121, a longer bond between the NZ of Lys-66 and the OD1 of the $\beta$-carboxylate and, finally, a bond of intermediate length between the backbone nitrogen of Lys-66 and OD2 of the $\beta$-carboxylate (Table III). In D121N, this last bond remains, although the component atoms have shifted nearly an angstrom, the bond is somewhat longer (3.17-3.24 $\AA$ ), and the oxygen is now part of a carboxamido group. However, both the bonds made previously by the NZ of Lys66 are gone. Instead, the NZ of Lys-66 now forms a hydrogen bond to the side chain oxygen, OD1, albeit a long one $(3.48$ $\AA$ ). As a result, the NZ of Lys-66 has been displaced $3.01 \AA$. These changes are accompanied in D $121 \mathrm{~N}$ by other significant movements throughout the 65-72 loop. One consequence is the formation of a hydrogen bond between the OE1 of Gln69 and the ND2 of Asn-67 with the concomitant loss of the hydrogen bond between the OE1 of Gln-69 and the ND2 of Asn-71. As a result, the ND2 of Asn-71 now forms a novel
FIG. 6. Comparison of residues 65-72. The structure of the loop comprising residues $65-72$ is shown in stereo for RNase 1-118:111-124 (solid line), $\mathrm{D} 121 \mathrm{~N}$ (dotted line), and D121A (dashed line). The structures were overlapped as in Fig. 2.

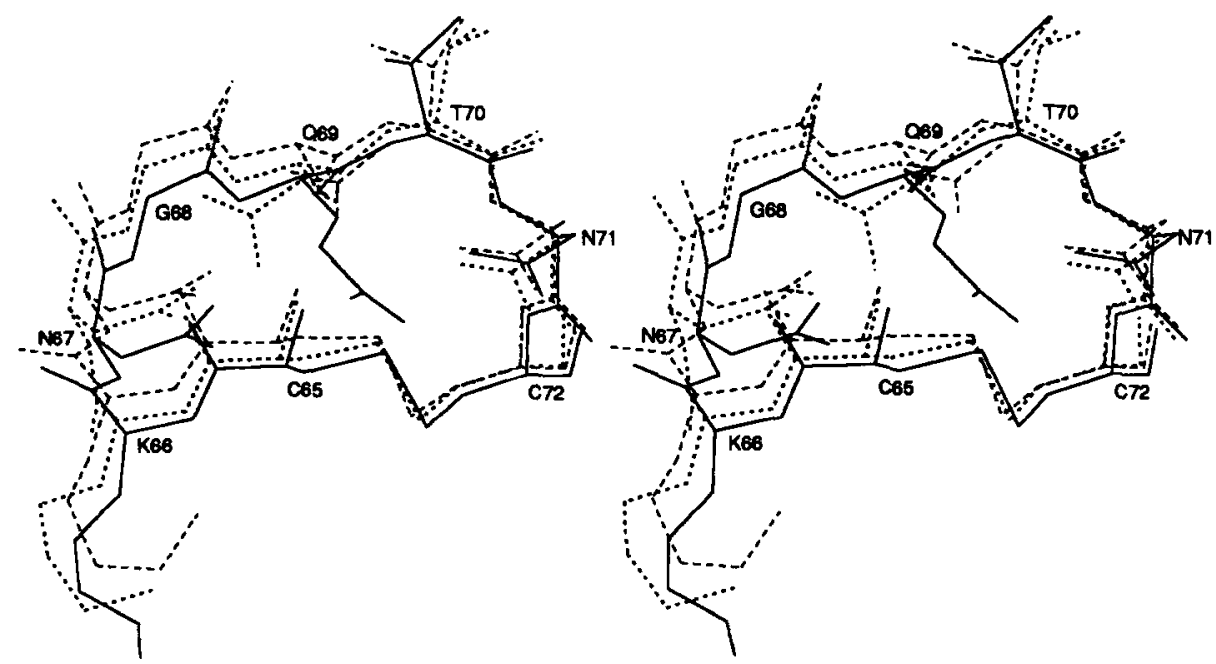


TABLE III Hydrogen bond distances $(\AA)$ at the active site

\begin{tabular}{|c|c|c|c|}
\hline Hydrogen bond & $\begin{array}{c}\text { RNase } \\
\text { 1-118:111-124 }\end{array}$ & D121N & D121A \\
\hline His-12 ND1 - Asn-44 OD1 & 3.22 & 3.26 & 3.38 \\
\hline His-12 ND1 - Thr -450 & 2.68 & 2.64 & 2.63 \\
\hline His-12 NE2 - Sul 12504 & 2.42 & 2.46 & 2.48 \\
\hline His- 119 ND1 - Sul 125 O2 & 2.93 & $2.96^{a}$ & $2.22^{b}$ \\
\hline His-119 NE2 - WAT 212 & 2.87 & & \\
\hline Lys-41 NZ - Gln-11 OE1 & 3.34 & 3.11 & 2.77 \\
\hline Lys-41 NZ - Asn-44 OD1 & 2.93 & 2.92 & 3.24 \\
\hline Lys-41 N - Tyr-97 OH & 3.18 & 3.12 & 3.03 \\
\hline Lys-41 O - Tyг-97 OH & 2.69 & $2.33^{b}$ & $2.32^{b}$ \\
\hline Lys-41 NZ - WAT 153 & 3.25 & 2.74 & 3.43 \\
\hline Gln-11 O - Lys-44 ND2 & 2.75 & 3.03 & 2.69 \\
\hline GIn-11 NE2 - Sul 125 O3 & 2.81 & & 3.25 \\
\hline Gln-11 OE1 - WAT 132 & 3.37 & & \\
\hline Gln-11 OE1 - WAT 183 & & 3.45 & \\
\hline Gln-11 NE2 - WAT 138 & 2.66 & 2.81 & 2.79 \\
\hline GIn-11 NE2 - WAT 228 & 2.83 & & \\
\hline Sul-125 O1 - WAT 153 & 2.69 & 2.74 & 3.00 \\
\hline Sul-125 O1 - WAT 197 & & & 2.81 \\
\hline Sul-125 O2 - Phe-120 N & 3.18 & 3.17 & \\
\hline Sul-125 O2-WAT 138 & 3.03 & & 3.26 \\
\hline Sul-125 O3-WAT 138 & 3.39 & & \\
\hline Sul-125 O3-WAT 153 & 3.13 & & 2.67 \\
\hline Sul-125 O3 - WAT 228 & 2.47 & & \\
\hline Sul-125 O4 - Phe-120 N & 3.25 & & 3.19 \\
\hline Sul-125 O4 - WAT 138 & 2.47 & 3.16 & 3.39 \\
\hline Sul-125 O4 - WAT 153 & 3.33 & 3.29 & 3.09 \\
\hline Lys-66 N - Asp-121 OD2 & 3.17 & & \\
\hline Lys-66 NZ - Ásx-121 OD1 & 3.44 & 3.48 & \\
\hline Lys-66 NZ - Asp-121 O & 2.79 & & \\
\hline Lys-66 N - Asn-121 OD1 & & 3.24 & \\
\hline
\end{tabular}

${ }^{a}$ The position of Sul $125 \mathrm{O} 2$ as well as that of His-119 ND1 has shifted in D121N. Moreover, the protein atom in this analog is CD2, not $\mathrm{ND1}$, as the imidazole ring appears to have flipped $180^{\circ} \mathrm{C}$; therefore, no hydrogen bond is actually present at this position in this analog. See "Active Site Sulfate Anion."

${ }^{b}$ This extremely short distance results from the inability of the refinement program to deal with a situation in which multiple positioning of a pair of atoms results in the appearance of an essentially constant electron density between them.

hydrogen bond to the carbonyl oxygen of Cys-110 while the OD1 of its side chain bonds with the proton from a water molecule, WAT 127. This water molecule is part of a water network not seen in RNase 1-118:111-124. WAT 127 is also hydrogen bonded to the NE2 of Gln-69 and, in addition, forms a good hydrogen bond to WAT 126 . As proposed in the Discussion, the presence of WAT 126 may be responsible for the greater loss of activity seen in D121N relative to D121A.

With D121A, no side chain hydrogen bonding is possible, and so all interaction with Lys-66 has been lost. Lys-66 in this analog does not form any novel hydrogen bonds with other atoms in the protein and its NZ is now displaced 4.21 $\AA$ from its position in RNase 1-118:111-124. The hydrogen bond between the OE1 of Gln-69 and the ND2 of Asn-71 has again been ruptured and has again been replaced by an interaction with a bridging water to which both side chains bond. This water is not coincident with the WAT 127 of D121N, however, and the water network to which it belongs has a structure completely different from that seen in the asparagine analog. Perhaps most importantly, the distance of the nearest approach made by any water molecule in this network to the CD2 position of His-119 (conventionally oriented) is $5.0 \AA$.

\section{DISCUSSION}

Study of the D121N and D121A derivatives of semisynthetic ribonuclease has shown that Asp-121 is required to
(A)
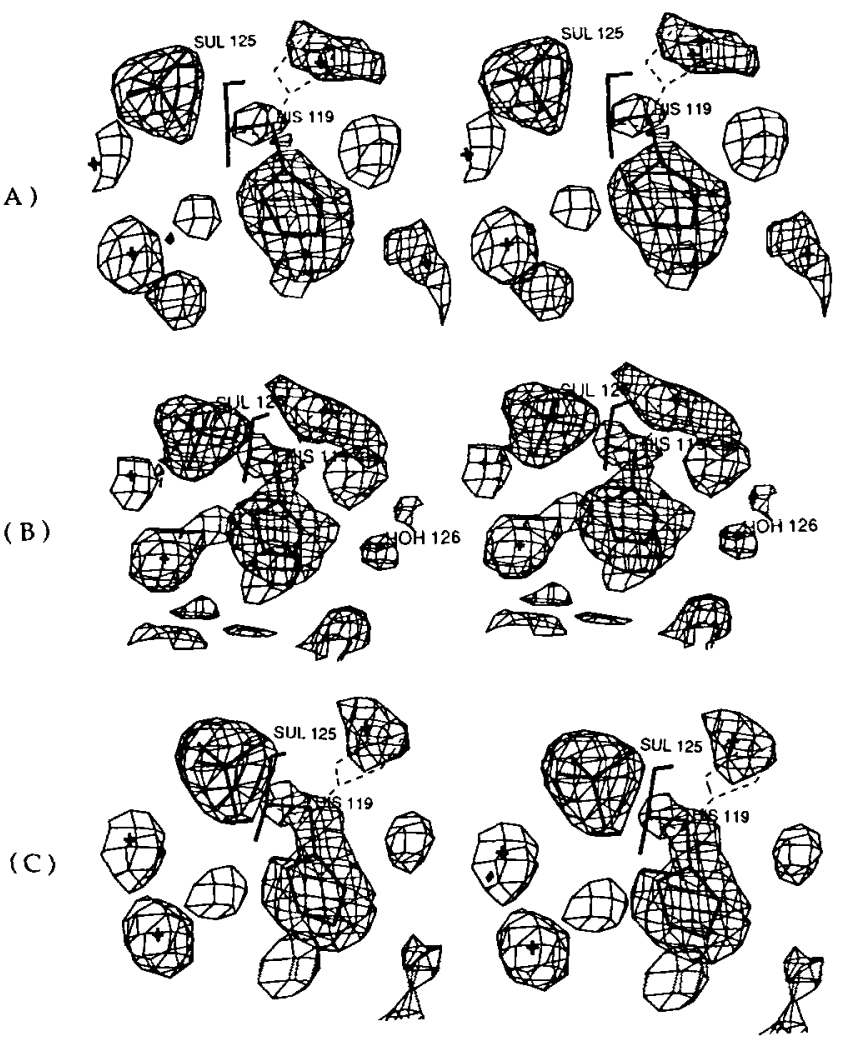

FIG. 7. Electron density for histidine 119. The density peaks for the A and $B$ positions of the imidazole ring of His-119 are shown for panel $A$, RNase 1-118:111-124; panel B, D121N; and panel $C$, $D 121 A$. The location of the side chain in position $B$ is shown with a solid line and the location in position $\mathrm{A}$ is shown with a dashed line. $P a n e l B$ also illustrates the positioning of WAT 126 (denoted as $H O H$ 126 ) with respect to His-119 in D121N. In panels $A$ and $C$, the $2 \mathrm{~F}_{0^{-}}$ $\mathrm{F}_{\mathrm{c}}$ density is contoured at the $2.5 \sigma$ whereas in panel $B$ it is contoured at $2.0 \sigma$.

achieve full catalytic activity. Although the overall structures of the D121N and D121A derivatives are very similar to that of the parent RNase 1-118:111-124 enzyme, as evidenced by $\mathrm{C}_{\alpha}$ RMS values below $0.4 \AA$, several localized structural changes of a greater magnitude have occurred. These changes, which are greater in number and size than the small structural variations noted previously between the parent complex and RNase A (Martin et al., 1987), include the movement of the loop containing residues 65-72 away from the active site, the rearrangement of hydrogen bonding networks and solvent molecules at the active site, a more or less generalized relocation of crystallographically bound solvent and, in the asparagine analog, a destabilization in the positioning of active site His-119. Most of the changes are far removed from the immediate site of the modifications and are distributed essentially throughout the molecule. Many are also unique to one or the other of the two analogs.

The $2.0 \AA$ structure of the $\mathrm{F} 120 \mathrm{Y}$ analog, ${ }^{3}$ which is fully active or hyperactive, depending upon the substrate used (Hodges and Merrifield, 1974) has provided a useful control concerning the degree to which the changes seen in D121N and in D121A may be caused by differences in measurements of the x-ray data or in the refinements. A comparison of the difference distance matrices (Nishikawa et al., 1972; Kundrot and Richards, 1987) for the $\mathrm{C}_{\alpha}$ positions of D121N, D121A,

${ }^{3}$ V. S. J. deMel, P. D. Martin, M. S. Doscher, and B. F. P. Edwards, manuscript in preparation. 
FIG. 8. The active site. The active site residues are shown in stereo for RNase 1-118:111-124 (solid line), D121N (dotted line), and D121A (dashed line). Solvent molecules are also plotted for RNase 1-118:111-124 $(\Delta)$, D121N $(+)$, and D121A $\left(^{*}\right)$. The sulfate ion is labeled X125.

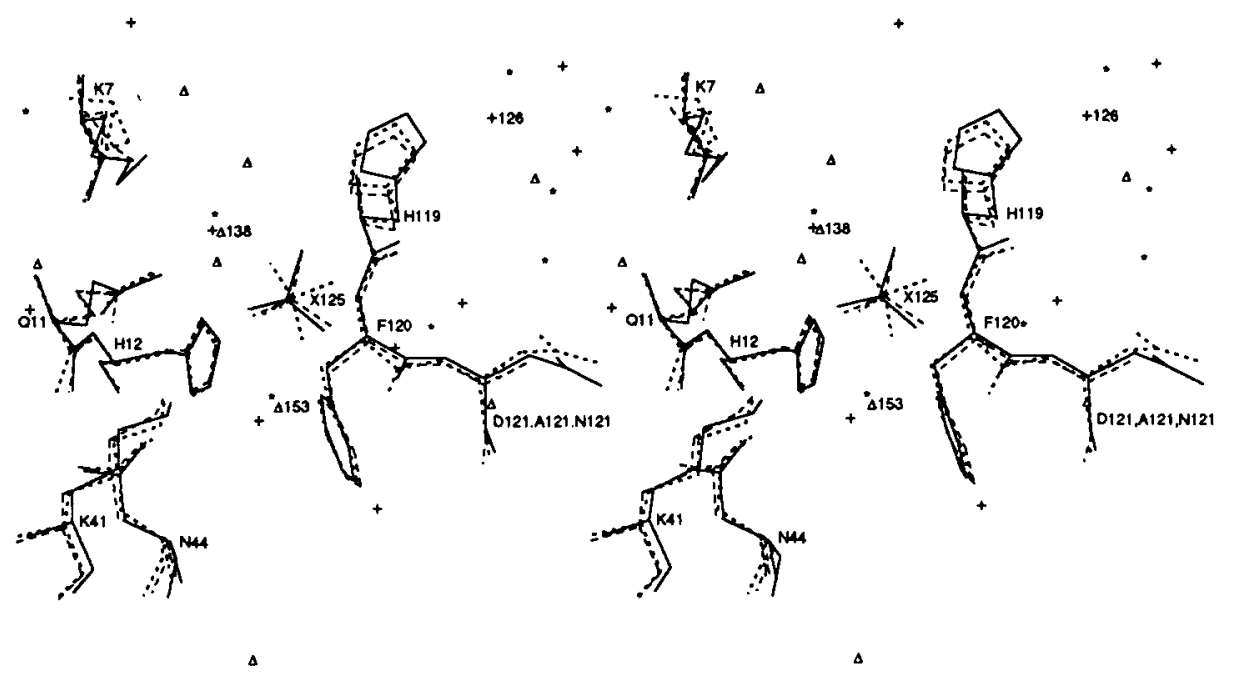

and F120Y indicates that the great majority of the changes are real (Fig. 9).

Comparable phenomena have been observed in staphylococcal nuclease, where the 1,400 -fold reduction in catalytic efficiency caused by replacing active site Glu- 43 with an aspartate is accompanied by structural rearrangements throughout the molecule (Hibler et al., 1987; Wilde et al., 1988; Loll and Lattman, 1990).

The only element of the active site which remains entirely unchanged by the Asn-121 and Ala-121 replacements is His12. The imperturbable nature of this side chain with respect to the binding of active site ligands (Wodak et al., 1977; Borkakoti, 1983; Borkakoti et al., 1983; Palmer et al., 1984; Howlin et al., 1987), to the presence of the putative transition state analog, uridine vanadate (Wlodawer et al., 1983), or to the removal from the active site of phosphate (Wlodawer et al., 1988) or sulfate (Campbell and Petsko, 1987) has been amply documented.

The existence of a second conformation for His-119 in the crystal has now been reported from three laboratories (Borkakoti et al., 1982; Martin et al., 1987; Nachman et al., 1990). In the first report, the occupancy of this second site, denoted position $B$, was minor $(0.20)$, but the same laboratory soon reported that the occupancy of position $B$ became 1.0 upon the binding at the active site of $\mathrm{O}^{3}-2^{\prime}$-CMP (Borkakoti, 1983; Palmer et al., 1984). In RNase 1-118:111-124, His-119 occupies position B predominantly (Martin et al., 1987), and in a chemically modified analog of RNase exhibiting no detectable activity in solution, His-119 also occupies position B (Nachman et al., 1990). His-119 moves from its more traditional conformation (Wlodawer et al., 1982; Borkakoti et al., 1982), now denoted position $\mathrm{A}\left(\chi 1=149^{\circ}\right)$, to position $\mathrm{B}(\chi 1=$ $-60^{\circ}$ ) by rotation around the $\mathrm{C}_{\alpha}-\mathrm{C}_{\beta}$ bond. All three laboratories have noted that the conformational flexibility of His-119 may be germane to the mechanism of action of the enzyme, but there is presently no direct evidence for this possibility. As indicated by the examples in Table IV, there is no correlation between the positioning of His-119 and the conditions used for crystallization, nor is there a correlation between the activity of the enzyme in solution and the positioning of His119. In their studies of the active site dynamics of RNase A, Brünger et al. (1985) noted that His-119 underwent dihedral angle transitions in some of the simulations and suggested that this freedom of movement might be important for the catalytic mechanism. Harris et al. (1987) have reported that a nonbonded potential energy map for His-119 reveals two discrete side chain positions with energy minima. Moreover, these positions, which correspond to the crystallographically observed $\mathrm{A}$ and $\mathrm{B}$ positions, are linked by a low energy pathway. No evidence for more than one His-119 conformer has ever been adduced in solution although extensive measurements of the C-2 proton NMR spectra of the histidine residues of various $R$ Nases have been made in many laboratories (Markley and Ulrich, 1984). No such evidence is to be expected, of course, if interconversion between conformers is occurring on a sufficiently rapid time scale.

Results of modeling studies carried out in this laboratory with structures containing active site ligands suggest, but do not prove, that site $B$ plays a role in the transphosphorylation step while site $A$ is active in the hydrolytic step. When the virtual substrate UpcA is at the active site, the distance between the C4P1 atom in this molecule, which has replaced an $\mathrm{O}^{\prime}$ atom in the actual substrate, UpA, and the ND1 of His- 119 , when in position $\mathrm{A}$, is $3.26 \AA$ whereas the corresponding distance is $2.68 \AA$ when His-119 is modeled in position B. The ND1 of His-119 is the atom postulated to protonate the $\mathrm{O5}^{\prime}$ of the scissile bond in a ribonucleotide phosphate during the transphosphorylation reaction (Wyckoff and Richards, 1971; Blackburn and Moore, 1982).

The $\mathrm{O} 2$ atom of uridine vanadate, a transition state analog for RNase, mimics the oxygen of the water molecule involved in the subsequent hydrolytic reaction (Lindquist et al., 1973). When uridine vanadate is placed in the active site of RNase 1-118:111-124, the $\mathrm{O} 2$ atom is positioned $2.96 \AA$ from the ND1 of His-119 in position A and $3.13 \AA$ from the ND1 of His-119 in position B. Thus, His-119 in site A is closer to the substrate atom that is attacked in the hydrolytic step while His-119 in site B is closer to the substrate atom that is attacked in the transphosphorylation step. However, in both cases His-119 in the more distant site is still close enough to react albeit less effectively than when it is in the closer site.

Prior to our findings, some evidence had accrued indicating that a change in the positioning of loop 65-72, and, in particular, the location of the side chain of Lys-66 might result in changes in enzymatic activity. In their study of sequence variation among mammalian pancreatic ribonucleases, Beintema et al. (1988) found several residues of this loop, including Lys-66, to be invariant across 40 species. Beintema (1989) also proposed that members of the ribonuclease superfamily must have a positive charge at position 66 or 122 to exhibit significant activity against the conventional RNase substrates. In RNase A and in our semisynthetic derivatives, 

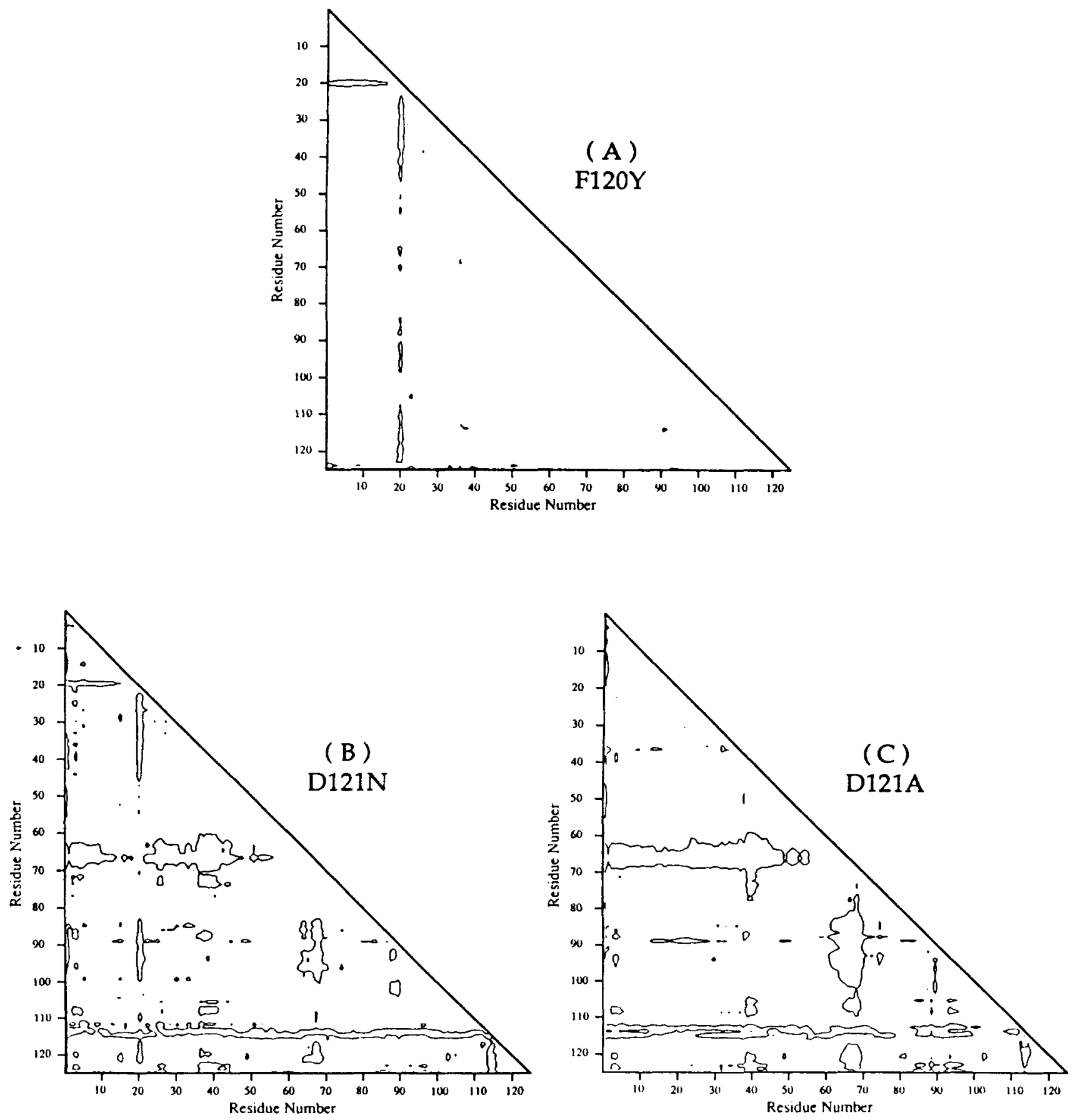

FIG. 9. Difference distance matrices. The matrices were constructed by subtracting the $C_{u}$ distance matrix for the refined RNase 1-118:111-124 structure from that for each of the analogs and contouring at $\pm 0.50 \AA$. The scales at the bottom and side of each panel represent residue numbers. Panel A, F120Y; panel B, D121N; panel C, D121A.

which have alanine in position 122 , this requirement is fulfilled by Lys-66. In complexes between RNase A and 8-oxoguanosine-2' phosphate (Borkakoti, 1983) or $\mathrm{O}^{3}-2^{\prime}$-CMP (Palmer et al., 1984), the NZ of Lys-66 approaches within hydrogen bonding distance of the $\mathrm{C}\left(5^{\prime}\right)$ hydroxyl group of the ribose moiety; such an interaction is not seen in the complex with 2 '-cytidylate, however (Howlin et al., 1987). In solution, as evidenced by proton NMR studies, the resonance position of the amide proton of Lys-66 responds to the titration of a group with a $\mathrm{p} K$ value of approximately 3 , a situation ascribed to the existence of a hydrogen bond between the main chain nitrogen of this residue and the carboxylate group of Asp-121 (Rico et al., 1989). The authors note that such a bond would be highly effective in anchoring together the two loops upon which these residues respectively reside.

In view of the multiplicity of changes, some of which involve intermolecular contacts, that have resulted from the replacement of Asp-121 by asparagine or alanine, any hypothesis concerning a detailed structural basis for the loss of catalytic efficiency in these analogs is necessarily speculative. The kinetic effects of the changes in solvent structure and hydrogen bonding are particularly obtuse because some are common to both derivatives and some are unique to one or the other. However, two major changes that are directly connected to the replacement of Asp121 are shared by both derivatives and may account for the activity loss seen in D121A as well as a 
TABLE IV

Absence of correlation between the positioning of His-119 and crystallization conditions or enzymatic activity in solution

\begin{tabular}{|c|c|c|}
\hline \multicolumn{3}{|c|}{ Crystallization conditions } \\
\hline Position of His- $119^{a}$ & Alcohol $^{b}$ & Salt $^{\mathrm{c}}$ \\
\hline $\mathrm{A}$ & RNase $A^{d}$ & U-H119-RNase $A^{e}$ \\
\hline B & RNase $\mathrm{A}+\mathrm{O}^{3}-2^{\prime}-\mathrm{CMP}^{\prime}$ & T-H12-RNase $A^{e}$; RNase $1-118: 111-124^{g}$ \\
\hline \multicolumn{3}{|c|}{ Enzymatic activity in solution } \\
\hline Position of His- $119^{a}$ & Active & "Inactive" \\
\hline $\mathrm{A}$ & RNase $\mathrm{A}^{h}$ & U-H119-RNase A (1\% active) ${ }^{i}$ \\
\hline $\mathrm{B}$ & RNase 1-118:111-124j & T-H12-RNase (no detectable activity) ${ }^{i}$ \\
\hline
\end{tabular}

${ }^{a}$ At least predominantly in the position indicated and, in some instances exclusively in the position indicated.

${ }^{b}$ Crystals grown from 30 to $40 \%$ aqueous ethanol, $\mathrm{pH}$ 5.2-5.7, as reported in Borkakoti et al. (1982) and Palmer et al. (1984).

${ }^{\circ}$ Crystals grown from $3.0 \mathrm{M} \mathrm{CsCl}, 1.1-1.3 \mathrm{M}$ ammonium sulfate, $\mathrm{pH}$ 5.1-5.2, as reported in Martin et al. (1987)

and Nachman et al. (1990).

${ }^{d}$ Borkakoti et al. (1982).

' Nachman et al. (1990).

' Palmer et al. (1984).

${ }^{k}$ Martin et al. (1987).

${ }^{\mathrm{h}}$ Kunitz (1939).

${ }^{i}$ Hummel et al. (1987).

${ }^{j}$ Lin et al. (1970).

significant portion of the activity loss seen in D121N. First, both derivatives are less electronegative than RNase 1118:111-124; and, second, the NZ of Lys-66, which has been identified by Beintema (1989) as an essential residue for RNase activity, has moved $3.0 \AA$ away from the active site in D121N and $4.2 \AA$ away in D121A.

The movement of Lys-66 also appears to be related to the unexpected observation that replacing Asp-121 with a polar, isosteric asparagine gives a worse enzyme $\left(k_{\text {cat }} / K_{M}=56 \mathrm{M}^{-1}\right.$ $\mathrm{s}^{-1}$ ) than replacing it with a smaller, hydrophobic alanine $\left(k_{\text {cat }} / K_{M}=250 \mathrm{M}^{-1} \mathrm{~s}^{-1}\right)$. The detailed consequences of the movement of Lys-66 differ for the two analogs, as described under "Lysine 66." In D121N, but not in D121A, a novel water molecule (WAT 126) is now positioned to stabilize a catalytically inactive conformer in which the imidazole ring of His- 119 has flipped $180^{\circ}$, placing the CD2 atom of this ring in the position normally occupied by ND1. The ND1 nitrogen now faces away from the active site and hydrogen bonds to WAT 126. As this conformer is almost certainly devoid of activity, the residual activity observed with D121N suggests that a small percentage of molecules retains the conventional His-119 ring conformation.

Thus, we see that the carboxylate of Asp-121 is necessary to stabilize the loop containing Lys-66 in the position that results in the greatest degree of catalysis. Also, we see that replacement of this residue by asparagine additionally results in the rearrangement of a water network, ultimately causing the destabilization of a catalytically competent conformation of His-119.

Asp-121 may have additional functions when His-119 is in position A. Others have noted that Asp-121 is within hydrogen bonding distance of His- 119 when this residue is in position A (Wlodawer and Sjölin, 1981; Wlodawer et al., 1982) and, on the basis of $a b$ initio molecular orbital calculations and molecule dynamics simulations, Brooks et al. (1986) proposed that Asp-121 is hydrogen bonded to His-119 during the hydrolytic step but not during the preceding transphosphorylation step; in this way, the necessary modulation of the "basicity" of His-119 is achieved during the course of the two successive reactions. As all the structures reported here have
His-119 predominantly in position B, they are not germane to an assessment of this proposed role for Asp-121.

Acknowledgments-We thank Michal J. Ram for excellent technical assistance. Amino acid and Edman sequence analyses as well as peptide syntheses were performed by the Wayne State University Macromolecular Core Facility.

\section{REFERENCES}

Anfinsen, C. B. (1956) J. Biol. Chem. 221, 405-412

Beintema, J. J. (1989) FEBS Lett. 254, 1-4

Beintema, J. J., Schuller, C., Irie, M., and Carsana, A. (1988) Prog. Biophys. Mol. Biol. 51, 165-192

Bernstein, F. C., Koetzle, T. F., Williams, G. J. B., Meyer, E. F., Brice, M. D., Rodgers, G. R., Kennard, O., Shimanouchi, T., and Tasumi, M. (1977) J. Mol. Biol. 112, 535-542

Blackburn, P., and Moore, S. (1982) in The Enzymes (Boyer, P. D., ed) 3rd Ed., Vol. 15, pp. 317-433, Academic Press, New York

Borkakoti, N. (1983) Eur. J. Biochem. 132, 89-94

Borkakoti, N., Moss, D. S., and Palmer, R. A. (1982) Acta Crystallogr. Sect. B Struct. Sci. 38, 2210-2217

Borkakoti, N., Palmer, R. A., Haneef, I., and Moss, D. S. (1983) J. Mol. Biol. 169, 743-755

Borkakoti, N., Moss, D. S., Stanford, M. J., and Palmer, R. A. (1984) J. Crystallogr. Spectrosc. Res. 14, 467-494

Brooks, C., III, Brünger, A., Francl, M., Haydock, K., Allen, L. C., and Karplus, M. (1986) Ann. N.Y. Acad. Sci. 471, 295-298

Brünger, A. T. (1988) J. Mol. Biol. 203, 803-816

Brünger, A. T., Brooks, C. L., III, and Karplus, M. (1985) Proc. Natl. Acad. Sci. U. S. A. 82, 8458-8462

Campbell, R. L., and Petsko, G. A. (1987) Biochemistry 26, 85798584

Cederholm, M. T., Stuckey, J. A., Doscher, M. S., and Lee, L. (1991) Proc. Natl. Acad. Sci. U. S. A. 88, 8116-8120

Doscher, M. S., Martin, P. D., and Edwards, B. F. P. (1983a) Biochemistry 22, 4125-4131

Doscher, M. S., Martin, P. D., and Edwards, B. F. P. (1983b) J. Mol. Biol. 166, 685-687

Findlay, D., Herries, D. G., Mathias, A. P., Rabin, B. R., and Ross, C. A. (1962) Biochem. J. 85, 152-153

Gutte, B., Lin, M. C., Caldi, D. G., and Merrifield, R. B. (1972) J. Biol. Chem. 247, 4763-4767

Harris, G. W., Borkakoti, N., Moss, D. S., Palmer, R. A., and Howlin, B. (1987) Biochim. Biophys. Acta 912, 348-356

Herries, D. G., Mathias, A. P., and Rabin, B. R. (1962) Biochem. J. 85, $127-134$ 
Hibler, D. W., Stolowich, N. J., Reynolds, M. A., Gerlt, J. A., Wilde, J. A., and Bolton, P. H. (1987) Biochemistry 26, 6278-6286

Hodges, R. S., and Merrifield, R. B. (1974) Int. J. Pept. Protein Res. 6, 397-405

Howard, A. J., Gilliland, G. L., Finzel, B. C., Poulos, T. L., Ohlendorf, D. H., and Salemme, F. R. (1987) J. Appl. Crystallogr. 20, 383-387 Howlin, B., Harris, G. W., Moss, D. S., and Palmer, R. A. (1987) J. Mol. Biol. 196, 159-164

Hummel, C. F., Pincus, M. R., Brandt-Rauf, P. H., Frei, G. M., and Carty, R. P. (1987) Biochemistry 26, 135-146

Irie, M., Miyoa, J., Mori, Y., Okada, Y., and Teno, N. (1988) Agric. Biol. Chem. 52, 1291-1292

Kundrot, C. E., and Richards, F. M. (1987) J. Mol. Biol. 193, 157170

Kunitz, M. (1939) Science 90, 112-113

Lin, M. C., Gutte, B., Moore, S., and Merrifield, R. B. (1970) J. Biol. Chem. 245, 5169-5170

Lin, M. C., Gutte, B., Caldi, D. G., Moore, S., and Merrifield, R. B. (1972) J. Biol. Chem. 247, 4768-4774

Lindquist, R. N., Lynn, J. L., and Lienhard, G. E. (1973) J. Am. Chem. Soc. 95, 8762-8768

Loll, P. J., and Lattman, E. E. (1990) Biochemistry 29, 6866-6873

Markley, J. L., and Ulrich, E. L. (1984) Annu. Rev. Biophys. Bioeng. $13,493-521$

Martin, P. D., Doscher, M. S., and Edwards, B. F. P. (1987) J. Biol. Chem. 262, 15930-15938

Merrifield, R. B., and Hodges, R. S. (1975) in Proceedings of the International Symposium on Macromolecules (Mano, E. B., ed) pp. 417-431, Elsevier Science Publishing Co., Amsterdam

Nachman, J., Miller, M., Gilliland, G. L., Carty, R., Pincus, M., and Wlodawer, A. (1990) Biochemistry 29, 928-937

Nishikawa, K., Ooi, T., Isogai, Y., and Saito, N. (1972) J. Physiol. Soc. Jpn. 32, 1331-1337
Okada, Y., Teno, N., Miyao, J., Mori, Y., and Irie, M. (1984) Chem. Pharm. Bull. (Tokyo) 32, 4585-4592

Palmer, R. A., Moss, D. S., Haneef, I., and Borkakoti, N. (1984) Biochim. Biophys. Acta 785, 81-88

Richards, F. M., and Wyckoff, H. W. (1973) in Atlas of Molecular Structures in Biology. I. Ribonuclease $S^{\prime}$ (Phillips, D. C., and Richards, F. M., eds) pp. 7-11, Clarendon, Oxford

Rico, M., Bruix, M., Santoro, J., Gonzalez, C., Neira, J. L., Nieto, J. L., and Herranz, J. (1989) Eur. J. Biochem. 183, 623-638

Rossman, M. G., and Argos, P. (1975) J. Biol. Chem. 250, 7525-7532

Sasaki, D. M., Martin, P. D., Doscher, M. S., and Tsernoglou, D. (1979) J. Mol. Biol. 135, 301-304

Sasaki, D. M., Kelly, C. E. R., Martin, P. D., Edwards, B. F. P., and Doscher, M. S. (1985) Arch. Biochem. Biophys. 24 1, 132-140

Stern, M. S. (1988) Aspartic Acid 121 Functions at the Active Site of Bovine Pancreatic Ribonuclease, Ph.D. thesis, Wayne State University, Detroit, MI

Stern, M. S., and Doscher, M. S. (1984) FEBS Let. 171, 253-255

Wilde, J. A., Bolton, P. H., Dell'Acqua, M., Hibler, D. W., Pourmotabbed, T., and Gerlt, J. A. (1988) Biochemistry 27, 4127-4132

Wlodawer, A., and Sjölin, L. (1981) Proc. Natl. Acad. Sci. U. S. A. 78, 2853-2855

Wlodawer, A., and Sjölin, L. (1983) Biochemistry 22, 2720-2728

Wlodawer, A., Bott, R., and Sjölin, L. (1982) J. Biol. Chem. 257, 1325-1332

Wlodawer, A., Miller, M., and Sjölin, L. (1983) Proc. Natl. Acad. Sci. U. S. A. 80, 3628-3631

Wlodawer, A., Svensson, L. A., Sjölin, L., and Gilliland, G. (1988) Biochemistry 27, 2705-2717

Wodak, S. Y,, Liu, M. Y., and Wyckoff, H. W. (1977) J, Mol. Biol. $116,855-875$

Wyckoff, H. W., and Richards, F. M. (1971) in The Enzymes (Boyer, P. D., ed) 3rd Ed., Vol, 4, pp. 647-806, Academic Press, New York 